\title{
Environmental Correlates of the Distribution of Planktivorous Fishes in the One Tree Reef Lagoon
}

\author{
R. E. Thresher* \\ Department of Biological Sciences, University of Sydney, Sydney, N.S.W. 2006, Australia
}

\begin{abstract}
Current theories conceming the determinants of community structure in coral reef fishes emphasize the stochastic elements associated with survival, dispersal and recruitment onto the reef of the planktonic larval stage typical of such fishes. To assess the significance of such elements on reef fish distribution, the present study compares the distribution on small patch reefs of several groups of 'normal' planktivorous fishes with that of Acanthochromis polyacanthus (Pomacentridae), a small planktivorous species that is well documented to lack such a planktonic dispersal stage. The comparison, based on repeated visual censuses of 26 reefs, revealed: (1) the abundance of $A$. polyacanthus correlated significantly with those of both nocturnal planktivores and diurnally active planktivores other than A. polyacanthus; (2) of 9 environmental variables examined, 3 (current strength, reef depth and abundance of the dominant piscivore Plectropomus leopardus), in one combination or another, dominated correlations with the distribution of all 3 groups; (3) A. polyacanthus appeared to be no more predictable in its occurrence than the 'normal' species. These results suggest that post-settlement factors alone, such as movement of juveniles and sub-adults and mortality due to piscivore activity, can account for much of the variance in abundance and unpredictability of occurrence characteristic of reef fishes. The distributions of the various planktivores are also discussed with respect to reef size, current strength and levels of piscivore activity.
\end{abstract}

\section{INTRODUCTION}

Although the extent of its role is still debated (e.g. Smith, 1978; Gladfelter et al., 1980; Anderson et al., 1981), most coral reef fish ecologists would agree that distribution and abundance of reef fishes is substantially influenced by the dispersing effect of a planktonic larval stage in the development of such fishes (reviewed by Helfman, 1978; Sale, 1980a; for a review of reef fish reproduction and development, see Thresher, in press a). As currently hypothesized, chance factors associated with larval survival, with settlement by metamorphosing individuals onto the reef, and with survival of post-metamorphic juveniles overlay deterministic patterns of habitat selection and competition, if any, in determining local abundance of a particular species. Accordingly, at best only a portion of the variation in abundance and distribution of any species is ever likely to be accounted for by quantifi-

- Present address: 367 North Avenue, Hilton, New York 14468, USA able habitat effects. Community structure, therefore, especially on smaller habitat patches (Sale, 1978: Gladfelter et al., 1980) will vary widely and unpredictably over time. Evidence to support this view is derived from studies of both artificial (e.g. Molles, 1978; Talbot et al., 1978) and natural reefs (e.g. Sale and Dybdahl, 1975, 1978; Doherty, 1980; in prep.; Sale and Douglas, in press.) and, with few exceptions, involve Indo-Pacific, rather than western Atlantic reef fishes (Sale, 1980a).

Like many such questions, the hypothesized role of chance processes associated with a planktonic larval stage is not amenable to direct experimental validation. Rather, proponents of the hypothesis derive predictions from it (e.g. there will be little year-to-year consistency in identity or intensity of recruitment to a particular habitat patch; the identity of present residents will have little or no effect on subsequent recruits) to test against the documented distribution of reef fishes, often with quite good fits (e.g. Doherty, in prep.). One particularly powerful prediction, however, has, as yet, gone untested. Species that lack a planktonic larval stage in their development should differ 
significantly from those with such a stage in terms of spatial and temporal variation in abundance. To date, only 2 species of coral-reef associated fishes are known or suspected to develop entirely on the reef. The first, Ogilbia cayorum (Brotulidae), suggested by observations made by Longley and Hildebrand (1941) and Suarez (1975), is probably common on western Atlantic reefs, but is extremely retiring and probably nocturnally active, making it an unsuitable subject for detailed ecological study. In contrast, the western Pacific pomacentrid Acanthochromis polyacanthus is not only well documented as lacking a planktonic stage (Robertson, 1973; Allen, 1975), but also is abundant and conspicuous on shallow reefs (Goldman and Talbot, 1976; Sale and Dybdahl, 1978; Thresher, in press b).

Acanthochromis polyacanthus is a small (maximum size approximately $90 \mathrm{~mm} \mathrm{S.} \mathrm{L.),} \mathrm{water-column} \mathrm{forag-}$ ing planktivore very similar to related fishes in the genus Chromis. Sub-adults, as well as a few adults, form large feeding aggregations over shallow reefs, reaching overall average densities on such reefs as high as 1.6 individuals $\mathrm{m}^{-2}$ (Thresher, in prep.). Most adults, however, are found in stable, heterosexual pairs. Spawning occurs primarily in late spring and early summer, at which time each pair produces one or more broods of up to 300 young. These free-swimming, planktivorous juveniles are defended by the adults until they reach an age of approximately $30 \mathrm{~d}$ and a size of about $20 \mathrm{~mm}$, at which time they 'fledge' and join with other newly fledged young to form immense aggregations. Spawning takes place principally, though not exclusively, on relatively large reef structures, and the young disperse from these reefs to surrounding patch reefs, often in small groups (Williams, 1979; 1980; own obs.).

The current study identifies the significant environmental correlates of the distribution of Acanthochromis polyacanthus, and other planktivorous reef fishes, on small patch reefs in the One Tree Reef Lagoon. The objectives are two-fold: first, to suggest those factors that may determine or constrain the distribution of such fishes, and second, by comparing $A$. polyacanthus with ecologically similar, 'normal' species, i.e. those with a prolonged planktonic dispersal phase, to obtain some indication of the magnitude of stochastic effects associated with this phase on the distribution and abundance of these fishes.

\section{MATERIALS AND METHODS}

Field work was done at the One Tree Island Field Station, southern Great Barrier Reef, between October, 1979, and February, 1980. The One Tree reef consists of a roughly triangular outer barrier reef surrounding a topographically complex lagoon. Primary lagoonal structures include numerous roughly circular reefs emergent at low tide, a complicated 'maze' of anastomizing reef, also emergent at low tide, and large numbers of completely submerged patch reefs, located principally between the central maze and the outer reef barrier (Fig. 1). These submerged reefs, on which the current work was done, range in diameter from less than $1 \mathrm{~m}$ to, rarely, as much as $20 \mathrm{~m}$.

Acanthochromis polyacanthus inhabits both emergent and submerged reefs in the lagoon, as well as extensive areas outside the lagoon. Twenty-six patch reefs, distributed throughout the main lagoon (Fig. 1), were selected for study on the basis of 4 criteria: First, each had to be relatively isolated from other coral outcrops, so that movement between reefs by at least the smaller reef fishes was limited. In practice, no reef was closer than $5 \mathrm{~m}$ to another reef and most were isolated by 15 to $20 \mathrm{~m}$ of open sand. Second, relatively small reefs were chosen, to facilitate visual censuses and measurement of physical characteristics. Selected reefs ranged in surface area from 3.6 to $53.8 \mathrm{~m}^{2}$, with a mean of $16.6 \mathrm{~m}^{2}$. Third, reefs were chosen so that as wide a range of physical characteristics, community structure, and distances from emergent reefs as possi. ble was represented. Finally, to fulfil the requirements of a concurrent study, all reefs were inhabited by at least 1 pair of adult $A$. polyacanthus. The number present ranged from 2 to 17 (exclusive of young of the year), with a mean of 5.4 individuals.

Physical attributes of the patches measured included maximum depth at slack low tide, maximum reef height, surface area, a topographic relief index, and percentage cover of various substrate types, using techniques based on Sale and Douglas (in press) and Sale (pers. comm.). A ruled transect line was laid along the long axis of the reef and pulled tight from edge to edge, resulting in a measured 'rounded' reef length. The line was then relaxed and a diver swam along it, pushing it into crevices and generally following the contours of the reef as closely as possible. A second diver followed and recorded the length of transect line subtended by each substrate type. (This procedure differs from Sale and Douglas, in press, which calculated percent cover based on 'rounded' rather than 'relaxed' lengths.) When completed, the tape was rotated $60^{\circ}$, and then to $120^{\circ}$, and the procedure repeated at each angle. The Topographic Relief Index was defined as the ratio between the summed 'relaxed' lengths and the summed 'rounded' lengths for all 3 transects. Percent substrate cover was calculated based on summed data for the 3 transects. Surface area of each reef was estimated by drawing an outline map of the reef while snorkeling over it, adjusting the map to 


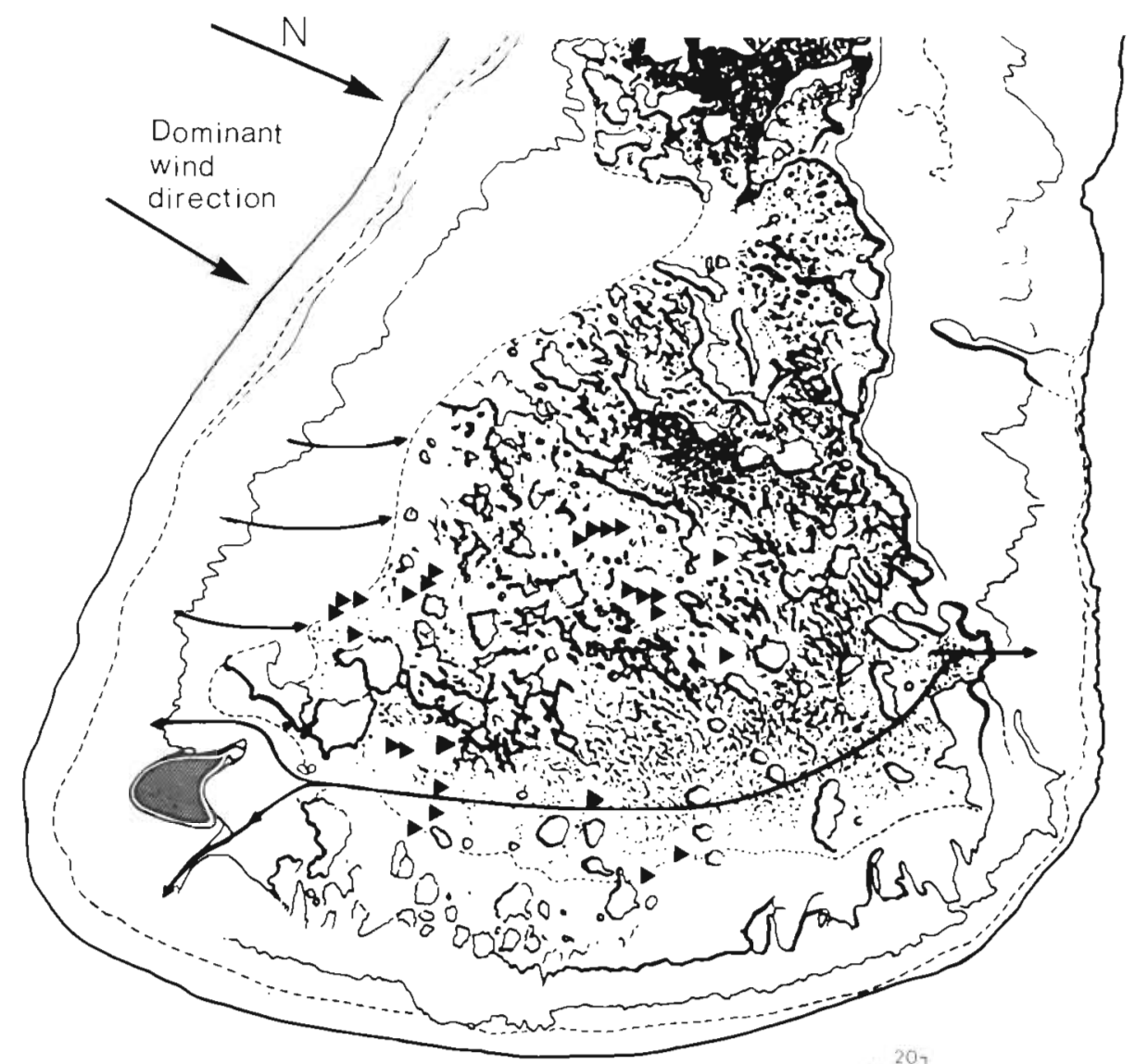

Fig. 1. Location of study reefs in One Tree lagoon and axes of highest current velocities. Distance from the island (shaded area) to major water egress point on the lee reef is approximately $3 \mathrm{~km}$

scale by means of the "rounded", rather than strictly horizontal measurements, and then measuring the area of the scaled representations by means of a gridded overlay. Two additional features were also determined for each reef. Distance from an emergent reef was measured on a high resolution aerial photograph of One Tree reef (Capricorn-Bunker Group, Film Number 052-061, run 26, frame 55, Kevron Aerial Surveys, Perth, Western Australia) and average current strength estimated, as ranks, by C. Ludington, who has just completed a detailed study of current patterns in the One Tree lagoon (Ludington, 1979; in prep.).

The population of planktivorous fishes residing on the patch reefs was determined by means of three visual censuses, one each at 2 -wk intervals, for each reef. All censuses were conducted between 15 October 1979 and 15 January 1980, with the general procedure following Sale and Douglas (in press). Census effectiveness is discussed in detail in Thresher (in press b). In general, comparison of the results of replicate visual censuses with immediately subsequent destructive censuses (Fig. 2) indicate that the former technique is effective primarily for fishes larger than 40 to $50 \mathrm{~mm}$ S. L. As emphasized by Sale (1980a, b) and Sale and Douglas (in press), it is critical that each study frame its conclusions only within the limits of the validity of its

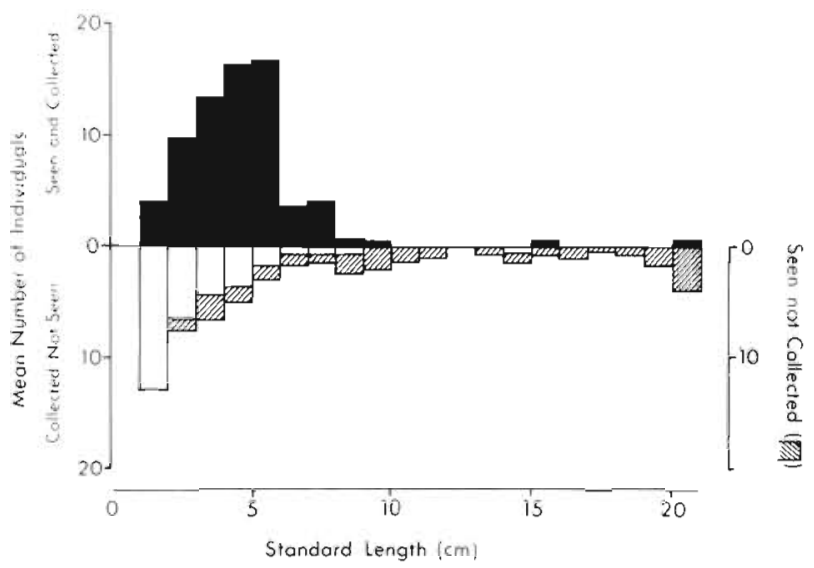

Fig. 2. Number of individuals observed on patch reefs in visual and destructive censuses as a function of Standard Length. Results of visual censuses are given as solid bars and hatched bars; those of destructive censuses are solid bars plus open bars. Data are mean values for each size class from censuses of 3 reefs

census techniques. Consequently, the present analysis is limited to relatively conspicuous species (mainly pomacentrids and the labrid, Cirrhilabrus sp.) that, on average, exceed $40 \mathrm{~mm} \mathrm{~S}$. L. Identification of fishes as planktivores was based on Hiatt and Strasburg (1960), Hobson and Chess (1978), Douglas (in prep.) and own observations. 
Table 1. Correlations between Independent Variables. Starred values are significant at $\mathrm{P}<0.05$

\begin{tabular}{|c|c|c|c|c|c|c|c|c|c|}
\hline & $\begin{array}{l}\text { Distance } \\
\text { from } \\
\text { emergent } \\
\text { reef }\end{array}$ & $\begin{array}{l}\text { Current } \\
\text { strength }\end{array}$ & $\begin{array}{c}\text { Surface } \\
\text { area }\end{array}$ & $\begin{array}{l}\text { Topo- } \\
\text { graphic } \\
\text { relief } \\
\text { index }\end{array}$ & $\begin{array}{l}\% \text { cover } \\
\text { branching } \\
\text { coral }\end{array}$ & $\begin{array}{c}\text { Maximum } \\
\text { reef } \\
\text { height }\end{array}$ & $\begin{array}{c}\text { Maximum } \\
\text { reef } \\
\text { depth }\end{array}$ & $\begin{array}{c}\text { Mean } \\
\text { number } \\
\text { P.leo- } \\
\text { pardus }\end{array}$ & $\begin{array}{c}\text { Mean } \\
\text { number } \\
\text { total } \\
\text { Piscivores }\end{array}$ \\
\hline Distance from emergent reef & $x$ & $0.65^{\circ}$ & -0.37 & -0.24 & -0.04 & -0.37 & -0.36 & 0.27 & 0.19 \\
\hline Current strength & & $\times$ & $-0.49^{\circ}$ & $-0.46^{*}$ & -0.14 & -0.36 & $-0.57^{\circ}$ & 0.35 & 0.22 \\
\hline Surface area & & & $x$ & 0.37 & $0.49^{\circ}$ & $0.45^{\circ}$ & 0.17 & -0.11 & -0.12 \\
\hline Topographic relief index & & & & $x$ & 0.17 & 0.06 & $0.45^{\circ}$ & -0.12 & -0.09 \\
\hline$\%$ cover branching coral & & & & & $\times$ & 0.20 & -0.31 & -0.29 & -0.29 \\
\hline Maximum reef height & & & & & & $\times$ & 0.36 & 0.19 & $0.42^{\circ}$ \\
\hline Maximum reef depth & & & & & & & $x$ & 0.22 & 0.33 \\
\hline Mean number $P$. leopardus & & & & & & & & $x$ & $0.75^{\circ}$ \\
\hline Mean number total Piscivores & & & & & & & & & $x$ \\
\hline
\end{tabular}

Data were analyzed by means of multiple regression techniques, using the REGRN program (IBM System/ 360 Scientific Subroutine Package) and the University of Sydney Cyber 170/730 computer. Multiple regression procedures were necessitated by the number of independent variables (9) tested against the distributions of the various planktivores and by the frequent correlations between these variables (Table 1). Statistical procedures, in general, follow Zar (1974).

\section{RESULTS}

Twenty-one planktivorous species averaging larger than $40 \mathrm{~mm} \mathrm{~S}$. L. inhabited the 26 study reefs (Table 2); Amphiprion melanotus, a symbiotic anemonefish, was not included in the analysis since its distribution was likely to be uniquely determined by the presence of suitable hosts. Otherwise, there were 12 species in the family Pomacentridae and 1 each in Labridae, Syngnathidae, Lutjanidae and Gobiidae, all of which are entirely diurnally active, and 4 species in the family Apogonidae, all of which were considered strictly nocturnal feeders. Aside from Acanthochromis polyacanthus, the number of diurnal planktivores resident ( = present for at least 2 of 3 censuses) on a reef ranged from 1 to $60(\bar{x}=12.5)$, the number of species observed, including transients, ranged from 2 to $7(\bar{x}=3.6)$, and the average number of reefs occupied by a species of diurnal planktivore ranged from 1 to $17(\overline{\mathrm{x}}=6,1)$. Comparable figures for the nocturnal planktivores are 0 to 33 individuals resident $(\bar{x}=4.8), 0$ to 3 species observed $(\overline{\mathrm{x}}=1.4)$, and 3 to 14 reefs occupied $(\overline{\mathrm{x}}=8.5)$ by a species.

The abundance of Acanthochromis polyacanthus on a reef correlated significantly with the summed abundance of all other diurnal planktivores, and with the abundance of nocturnal planktivores (Table 3, Fig. 3). There was also a trend $(p<0.10)$ for correlated numbers of nocturnal and diurnal (other than $A$. polyacan-
Table 2. Planktivorous fishes present on study reefs

\begin{tabular}{|c|c|c|}
\hline Family, species & $\begin{array}{l}\text { Number of } \\
\text { reefs } \\
\text { occupied }\end{array}$ & $\begin{array}{l}\text { Mean } \\
\text { number } \\
\text { resident }\end{array}$ \\
\hline \multicolumn{3}{|l|}{ Pomacentridae } \\
\hline Abudefduf coelestinus & 12 & 0.65 \\
\hline Acanthochromis polyacanthus & 26 & 5.28 \\
\hline Amphiprion melanopus & 2 & 0.46 \\
\hline Chromis caeruleus & 5 & 0.77 \\
\hline C. nitida & 3 & 1.50 \\
\hline Dascyllus aruanus & 13 & 4.32 \\
\hline D. reticulatus & 1 & 0.15 \\
\hline D. trimaculatus & 1 & 0.04 \\
\hline Neopomacentrus azysron & 1 & 0.04 \\
\hline Pomacentrus australis & 6 & 0.23 \\
\hline P. pavo & 2 & 0.12 \\
\hline P. popei & 17 & 2.92 \\
\hline$P$. sp. & 14 & 1.73 \\
\hline \multicolumn{3}{|l|}{ Labridae } \\
\hline Cirnhilabrussp. & 17 & 2.28 \\
\hline \multicolumn{3}{|l|}{ Syngnathidae } \\
\hline Corythoichthys paxtoni & 2 & 0.12 \\
\hline \multicolumn{3}{|l|}{ Gobiidae } \\
\hline Amblygobius rainfordi & 1 & 0.08 \\
\hline \multicolumn{3}{|l|}{ Lutjanidae } \\
\hline Pterocaesio diagramma & 6 & 0.08 \\
\hline \multicolumn{3}{|l|}{ Apogonidae } \\
\hline Apogon cyanosoma & 4 & 0.12 \\
\hline A. doderoleini & 13 & 3.57 \\
\hline A.sp. & 3 & 0.12 \\
\hline Cheilodipterus quinquelineatus & 14 & 0.69 \\
\hline
\end{tabular}

thus) planktivores. The broad correlations between the abundance of the 3 'types' of planktivores is also reflected in the similar environmental factors that correlate with the abundance of each (Table 4). Contrary to expectations, distance from an emergent reef did not prove to correlate significantly with the abundance of A. polyacanthus once other factors were taken into account. Rather, abundance of the species correlated 
Table 3. Coefficients for correlations between abundance of Acanthochromis polyacanthus and both number of individuals and number of species of nocturnal planktivores and diurnal planktivores other than $A$. polyacanthus. Starred values are significant at $\mathrm{P}<0.05$

\begin{tabular}{|c|c|c|c|c|}
\hline & $\begin{array}{c}\text { Acanthochromis } \\
\text { polyacanthus }\end{array}$ & $\begin{array}{c}\text { Diurnal } \\
\text { planktivores }\end{array}$ & $\begin{array}{c}\text { Nocturnal } \\
\text { planktivores }\end{array}$ & \\
\hline Acanthochromis polyacanthus & $x$ & 0.364 & $0.485^{\circ}$ & \multirow{4}{*}{$\begin{array}{l}\text { Number } \\
\text { of species }\end{array}$} \\
\hline Diurnal planktivores & $0.413^{\circ}$ & $x$ & 0.369 & \\
\hline Nocturnal planktivores & $L^{0.475^{\circ}}$ & 0.364 & $\times$ & \\
\hline \multicolumn{4}{|c|}{ Number of individuals } & \\
\hline
\end{tabular}

Table 4. Environmental correlates of the distribution of planktivores on the study reefs. Results are end-points of step-down multiple regressions

\section{Acanthochromis polyacanthus}

$Y=-7.49+0.44 X_{1}+2.58 X_{2}-4.41 X_{3}$

where: $Y=$ Number of individuals; $X_{1}=$ current strength; $X_{2}=$ reef depth; $X_{3}=$ mean abundance of

Plectropomus leopardus

$$
\begin{aligned}
& r^{2}=0.37 \\
& F_{3,22}=4.22 \\
& P<0.02
\end{aligned}
$$

Nocturnal planktivores

$$
\begin{aligned}
& Y_{1}=-18.7+0.63 X_{1}+8.43 X_{2}-4.24 X_{3} \\
& r^{2}=0.32 \\
& \text { and } \\
& F_{3,22}=3.45 \\
& P<0.04
\end{aligned}
$$

relief index; $X_{3}=$ mean abundance of $P$. leopardus

Diurnal planktivores, other than A. polyacanthus

$$
\begin{aligned}
& Y_{1}=-0.37+0.09 X_{1}+0.86 X_{2} \\
& \text { and } \\
& Y_{2}=-4.41+0.22 X_{1}+1.66 X_{2} \\
& r^{2}=0.23 \\
& F_{2,23}=3.42 \\
& P=0.05 \\
& r^{2}=0.25 \\
& \text { where: } Y_{1}=\text { Number of species; } Y_{2}=\text { number of juvenile individuals; } X_{1}=\text { current strength; } X_{2}=\text { reef } F_{2,23}=3.91 \\
& \text { depth } \\
& p<0.04
\end{aligned}
$$

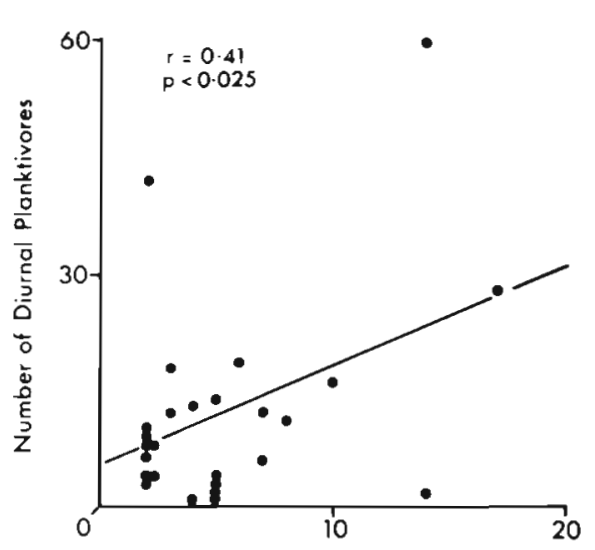

Number of A. polyacanthus

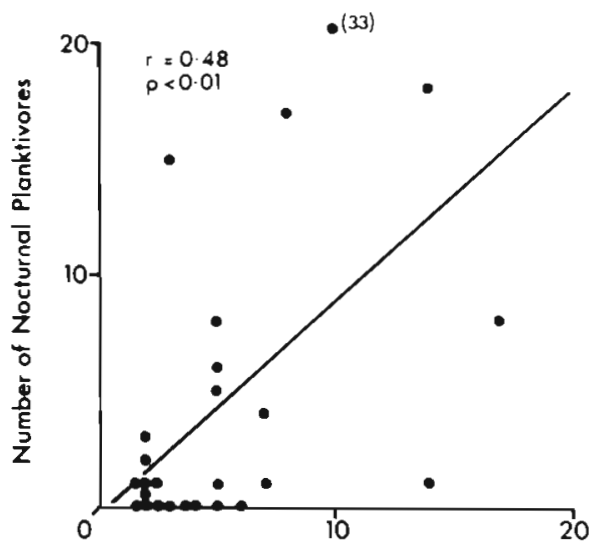

Number of $\underline{A}$. polyocanthus
Fig. 3. Correlations between the abundance of Acanthochromis polyacanthus and, respectively, diurnal planktivores other than A. polyacanthus, and nocturnal planktivores 
significantly with 3 variables: current strength and reef depth (both positively) and the abundance of the piscivore Plectropomus leopardus (negatively). In combination, the 3 account for $37 \%$ of the variation in abundance of $A$. polyacanthus on the study reefs. Two of these factors, current strength and the abundance of $P$. leopardus, also correlated significantly with the abundance of nocturnal planktivores. Again, abundance increased with current strength and decreased with increasing mean numbers of the piscivore. In addition, abundance of nocturnal planktivores was also significantly correlated with topographic relief (most abundant on complex reefs). In combination, current strength, the number of $P$. leopardus, and topographic relief accounted for $32 \%$ of the variance in numbers of individuals and $34 \%$ of the variance in number of species of nocturnal planktivores.

The number of species of diumally active planktivores, other that Acanthochromis polyacanthus, present on a reef also correlated significantly with 2 of the 3 variables that proved significant for $A$. polyacanthus: the number of species increased with both increased current strength and increased reef depth $\left(r^{2}=0.23\right)$. The summed abundance of diurnal planktivores, other than $A$. polyacanthus, however, neither correlated significantly with any single environmental variable, nor with any combination of variables. Analysis of the 3 most abundant of these species (Table 5) suggests why no single correlation for all diurnal planktivores was possible. Each of the 3,2 pomacentrids and a labrid, either correlated significantly or tended to correlate with a different sub-set of the variables measured: the abundance of Dascyllus aruanus correlated with reef height and depth; that of Cirrhilabrus sp. tended to correlate with topographic relief and distance from an emergent reef; and that of Pomacentrus popei weakly tended to correlate with current strength and distance from an emergent reef. The diversity of diurnal planktivores and, apparently, the particular pattern of habitat occupancy by each precludes any general predictive relationship for the group as a whole. Predictability for any one species ranged from a low of $15 \%$ for $P$. popei to a high of $39 \%$ for $D$. aruanus.

Finally, the predominance of current strength as a positive correlate of the abundance of planktivores could result from two mechanisms: either the fish settle on all reefs, but survive only on reefs in strong current areas, or recruitment is positively correlated with current strength. Analysis of the abundance of juvenile diumally-active planktivorous species other than Acanthochromis polyacanthus indicated a significant positive correlation with current strength and reef depth (Table 4), suggesting the latter rather than the former mechanism. The data do not permit discrimination between active habitat selection and a passive response based on reefs in higher current regimes being exposed to more planktonic larvae. The differences in correlates of distribution between diurnallyactive species, discussed above, however, suggests some process of active habitat selection.

\section{DISCUSSION}

Of the 9 independent variables examined, only 3 proved not to contribute significantly to correlations with planktivore distribution: percent branching coral cover, which was expected to influence distribution of Dascyllus aruanus, based on Sale $(1971 \mathrm{a}, \mathrm{b})$, mean number of all piscivores, rather than number of Plectropornus leopardus alone, and, most surprisingly, reef size. Even a casual survey of patch reefs in the One Tree lagoon suggests a conspicuous correlation between reef fish abundance and reef size, a point abundantly confirmed by Sale and Douglas (in press). In a 30-mo study, involving 20 patch reefs in the One Tree lagoon, they found that reef fish abundance correlated only with reef size, this single factor account-

Table 5. Environmental correlates of the distribution of the 3 most abundant diurnal planktivores, other than Acanthochromis polyacanthus, present on the study reefs. Results are end-points of step-down multiple regressions

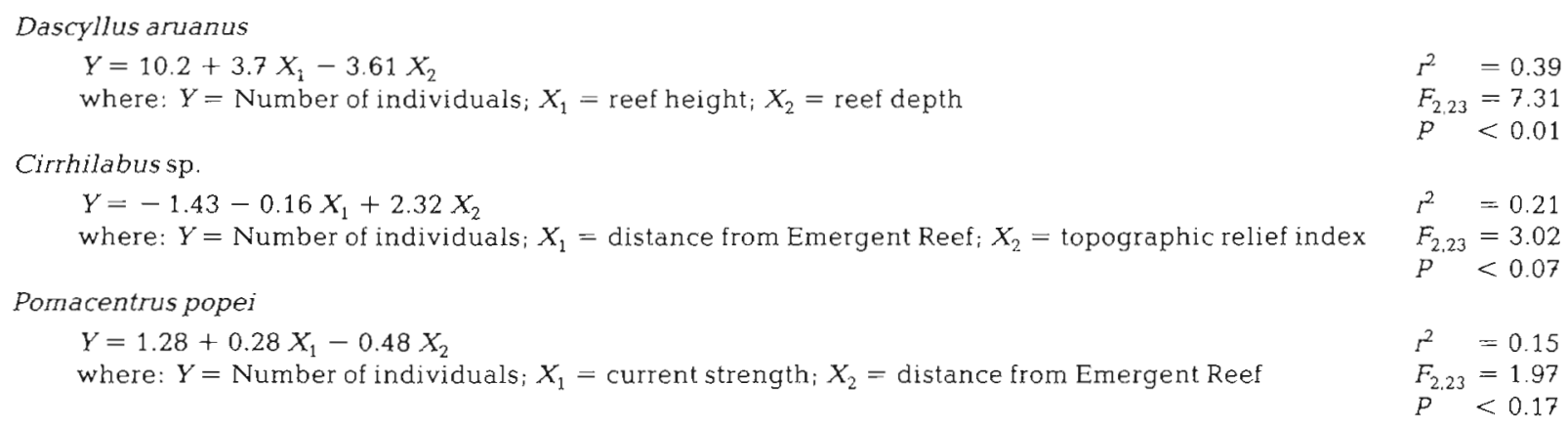

$$
\begin{aligned}
& r^{2}=0.39 \\
& F_{2,23}=7.31 \\
& p<0.01 \\
& r^{2}=0.21 \\
& F_{2.23}=3.02 \\
& P^{2}<0.07 \\
& r^{2}=0.15 \\
& F_{2,23}=1.97
\end{aligned}
$$$$
P<0.17
$$ 
ing for $77 \%$ of the variance in individual abundance. Similarly, reef size accounted for $67 \%$ of the variance in number of species present, with only percent live coral cover significantly improving the correlation. Williams (1979) also found a trend towards increasing abundance of planktivorous pomacentrids with increasing reef size for patches in 3 of 4 broad study areas in the One Tree lagoon. The difference between these studies, on the one hand, and the present study, on the other, appear to derive from 2 factors. First, the earlier studies, and especially Sale and Douglas (in press), differ from the present one in emphasis and objectives, such that deliberate choice of study reefs in each to a large extent accounts for the different conclusions. Because they were concerned mainly with temporal variation in community structure and in effects of reef physical characteristics on this structure, Sale and Douglas (in press), by design, selected for study reefs that were at relatively uniform depths, subject to comparable current regimes, and relatively close to one another, in order to minimize such possibly confounding effects on the variables of primary interest. In contrast, the present study involved reefs widely dispersed about the lagoon, in a deliberate effort to detect effects of current strength, reef depth, and the like. The results of the 2 studies combine to suggest that current strength and water depth are important correlates of planktivore distribution over the lagoon as a whole, but that on a local scale the size of the reef may become a factor of primary importance. The second critical difference between the earlier studies and the present one is the size of the reefs involved, with the former studies focusing on patch reefs substantially smaller than those examined here. Williams' (1979) reefs, depending upon the study area, ranged in average volume from 0.84 to $1.18 \mathrm{~m}^{3}$; the latter had an average surface area only a third that of the average reef in this study (approximately $5.5 \mathrm{~m}^{2}$ vs. $16.6 \mathrm{~m}^{2}$ ). Similarly, the mean reef examined by Sale and Douglas (in press) had a surface area just under half that of currently examined reefs $\left(8.25 \mathrm{~m}^{2}\right.$ vs. $\left.16.6 \mathrm{~m}^{2}\right)$. The positive correlations between planktivore abundance and reef size obtained by Sale and Douglas (in press) and Williams (1979) combine with results of the present study to suggest that reef size is important only to some upper limit. This conclusion is also suggested by data provided by Williams (1980), who found no correlation between reef size and planktivore abundance in a small set of reefs of larger average volume than he considered earlier (mean volume $2.06 \mathrm{~m}^{3}$ vs. $1.03 \mathrm{~m}^{3}$ ) (area of the former approximately $10 \mathrm{~m}^{2}$ ). The small sample size of his later study $(n=12)$, however, precludes drawing any strong inferences. Overall, the comparison of results across the different studies suggests that attempts to generalize determinants of com- munity structure across an extreme range of reef sizes are likely to be unsuccessful, since quite different factors appear to be important at either end of the size range.

The central role of current strength, correlating positively with abundance of Acanthochromis polyacanthus and nocturnal planktivores and with both number of species and number of juveniles of diurnal planktivores other than $A$. polyacanthus, is consistent with models of community structure suggested by Sale and his co-workers (reviewed by Sale, 1980a) and Talbot et al. (1978), and supports similar suggestions made by de Boer (1978), Hobson and Chess (1978) and Williams (1979). Hobson and Chess, however, further suggest that the effects of current strength differ between nocturnal and diurnal planktivores, a suggestion not immediately supported by the present results. Specifically, Hobson and Chess suggest that nocturnally active planktivores should be most abundant in areas with weak currents, and a diurnal species most abundant in areas of strong currents, a difference they correlate with the different prey items taken by and the foraging behaviour characteristic of each group. The present study, in contrast, found both groups correlating positively with current strength. While this apparent difference could reflect real differences in the biology of the fishes in the 2 study sites, it is more likely a function of the range of current strengths considered. Hobson and Chess report maximum current strengths at Enewetak Atoll of $90 \mathrm{~cm} \mathrm{~s}^{-1}$, whereas Ludington (pers. comm.) found the strongest currents in the One Tree lagoon proper to be only about onetenth this value. The 2 studies, in fact, complement one another, to suggest that abundances of both nocturnally and diurnally active planktivores are a positive function of current strength at low speeds, but that the former reach a peak in abundance at current strengths well below that of diumal species. That these latter fishes also decline after reaching a peak abundance at some optimal current velocity is suggested by both Hobson and Chess (1978), who found that feeding rates by these fishes declined at the strongest currents studied, and by Thresher (in prep.), who found that reproductive success of $A$. polyacanthus declined in areas of consistently very strong currents.

The role of predation in shaping the behaviour and ecology of coral reef fishes has also been widely speculated upon (e.g. Hartline et al., 1972; Ehrlich et al., 1977; Johannes, 1978; Talbot et al., 1978; Thresher, in press a), in many cases with respect to evolutionary hypotheses that are not readily amenable to direct testing. Evidence that predators are shaping community composition, however, should be obtainable although, as emphasized by Sale (1980a), no such evidence has yet been provided. The present data, 
while clearly not substituting for well designed experimental manipulations, provides such evidence. Data (Thresher, in press b) document a significant correlation between the likelihood that an adult Acanthochromis polyacanthus would disappear from a patch reef and the abundance of the coral trout Plectropomus leopardus on that reef. The present study supports and extends this conclusion, with the number of coral trout seen on a reef correlating signficantly, and negatively, with the abundance of both $A$. polyacanthus and nocturnal planktivores. On a broader scale, there is also a suggestive correlation between the low overall densities of $A$. polyacanthus on outer reef slopes (Thresher, in prep.), despite high rates of growth and fecundity, and the highest densities of $P$. leopardus being found in such areas (Choat, 1968). While correlation does not prove causation, it is difficult to imagine why a roving predator like $P$. leopardus would be attracted to reefs that had low numbers of planktivores, which constitute a significant portion of its diet (Choat, 1968; Goeden, 1978), independent of effects of current strength and reef depth.

Results of the present study, therefore, are consistent with the hypothesis, advanced by Talbot et al. (1978) and Sale (1980a), among others, that the abundance of fishes on a patch reef is the result of a balance between recruitment (either as juveniles, in the case of Acanthochromis polyacanthus, or as juveniles and, probably, roving adults, in the case of nocturnal planktivores) and mortality due to piscivore activities. Even so, the combined effects of both positive and negative correlates of abundance still account, at best, for only about a third of the variance in number of individuals present. The remainder, and major part of the variance must be due either to physical or biotic factors not yet examined, or, as advocated by Sale and his co-workers (Sale, 1977, 1978, 1979, 1980a, b; Williams, 1979; Doherty, 1980) and by Talbot et al. (1978), to chance processes associated with recruitment and survival. There is no evidence yet presented that factors such as current strength, reef depth and piscivore activity rigorously constrain community structure. Rather, such factors appear to place broad environmental limits on the distribution of reef fishes, within which the animals are distributed in a non-random (e.g. effects of habitat selection), but 'sloppy' fashion.

The extent to which community structure is determined by recruitment-associated events, however, is still being argued, as discussed in the Introduction. Returning to the principal objective of this study, there is a remarkable similarity between the distribution of Acanthochromis polyacanthus and those of nocturnal and other diurnal planktivores, despite fundamentally different patterns of reproduction and juvenile dispersal. Not only did the abundance of $A$. polyacanthus correlate significantly with those of 'water-columndispersed' planktivores, but also the same environmental factors that correlated with the distribution of these latter species - reef depth, current strength, and the abundance of Plectropomus leopardus - also correlated with the distribution of $A$. polyacanthus. Moreover, the demersally reproducing species appears to be no more predictable in its occurrence, at least on the basis of the variables considered, than are planktonically dispersed groups. This latter conclusion is not robust, based as it is on comparison of the end points of a multiple regression analysis. However, combined with the similar distributions of $A$. polyacanthus and other planktivorous groups and their nearly identical correlates in the multiple regression, it does suggest that on the small habitat patches typically studied post-settlement events alone can account for much of the observed variance in spatial distribution of reef fishes. Chance processes associated with recruitment from the plankton may not necessarily be the major 'randomizing' element in determining the local distribution of the species. Its effects on temporal variation in abundance are less clear. Doherty (1980), for example, presents data supporting and argues for considerable year-to-year variation in recruitment intensity, apparently derived from yearly differences in larval success in the water column. If so, presumably annual variations in the abundance and recruitment of A. polyacanthus, lacking a planktonic stage, would be less dramatic, or at least out of phase with those of 'normal' species. Long term comparisons of $A$. polyacanthus with such species may provide a useful test of this hypothesized effect of planktonic development on the structuring of reef fish communities.

Acknowledgements. I particularly thank A. M. Gronell for assistance in the field and discussion of concepts as they developed, and Dr. P. F. Sale who not only discussed these results with me at length, but who aIso made available material not yet in press. I also thank Dr. P. J. Doherty for very useful discussions and C. A. Ludington for information regarding current patterns in the One Tree lagoon. This work was supported by grants from the Australian Research Grants Committee, the University of Sydney and, especially, a Queen's Fellowship in Marine Science. This is a contribution from the One Tree IsIand Field Station, University of Sydney.

\section{LITERATURE CITED}

Allen, G. R. (1975). Damselfishes of the South Seas, Tropical Fish Hobbyist, Neptune, New Jersey

Anderson, G. R. V., Ehrlich, A. H., Ehrlich, P. R., Roughgarden, J. D., Russell, B. C., Talbot, F. H. (1981). The community structure of coral reef fishes. Am. Nat. 117: $476-495$

Choat, J. H. (1968). Feeding habits and distribution of Plectropomus maculatus (Serranidae) at Heron Island. Proc. R. Soc. Queensland 80: 13-18 
de Boer, B. A. (1978). Factors influencing the distribution of the damselfish Chromis cyanea (Poey), Pomacentridae, on a reef at Curacao, Netherlands Antilles. Bull. mar. Sci. 28: $550-565$

Doherty, P. J. (1980). Biological and physical constraints on the populations of two sympatric territorial damselfishes on the southern Great Barrier Reef. Ph.D. Dissertation University of Sydney

Ehrlich, P. R., Talbot, F. H., Russell, B. C., Anderson, G. R. V (1977). The behaviour of chaetodontid fishes with special reference to Lorenz's 'poster colouration' hypothesis. J. Zool., Lond. 183: 213-228

Gladfelter, W. B., Ogden, J. C., Gladfelter, E. H. (1980) Similarity and diversity among coral reef fish communities: a comparison between tropical western Atlantic (Virgin Islands) and tropical central Pacific (Marshall Islands) patch reefs. Ecology 61: 1156-1168

Goeden, G. B. (1978). A monograph of the coral trout Plectropomus leopardus (Lacepede). Qld. Fish. Serv., Res. Bull. 1: 1-42

Goldman, B., Talbot, F. H. (1976). Aspects of the ecology of coral reef fishes. In: Jones, D. A., Endean, R. D. (eds.) Blology and geology of coral reefs, Vol. IV. Academic Press, New York, pp. 125-154

Hartline, A. C., Hartline, P. H., Szmant, A. M., Flechsigg, A. O. (1972). Escape response in a pomacentrid reef fish, Chromis cyaneus. Nat. Hist. Mus. Los Angeles Cty., Sci. Bull. (14): 93-97

Helfman, G. S. (1978). Patterns of community structure in fishes: summary and overview. Env. Biol. Fish. 3: 129-148

Hiatt, R. W., Strasburg, D. W. (1960). Ecological relationships of the fish fauna on coral reefs of the Marshall Islands. Ecol. Monogr. 30: 65-127

Hobson, E. S., Chess, J. R. (1978). Trophic relationships among fishes and plankton in the lagoon at Enewetak Atoll, Marshall Islands. Fish. Bull. U. S. 76: 133-153

Johannes, R. E. (1978). Reproductive strategies of coastal marine fishes in the tropics. Env. Biol. Fish. 3: 65-84

Longley, W. H., Hildebrand, S. F. (1941). Systematic catalog of the fishes of Tortugas, Florida, with observations on color, habits, and local distribution. Carnegie Inst. Wash. Publ. (535): 1-331

Ludington, C. A. (1979). Tidal modifications and associated circulation in a platform reef lagoon. Aust. J. mar. Freshwat. Res. 30: $425 \quad 430$

Molles, M. C. (1978). Fish species diversity on model and natural reef patches. Experimental insular biogeography. Ecol. Monogr. 48: 289-305

Robertson, D. R. (1973). Field observations on the reproduc- tive behaviour of a pomacentrid fish., Acanthochromis polyacanthus. Z. Tierpsychol. 32: 319-324

Sale, P. F (1972a). Influence of corals in the dispersion of the pomacentrid fish, Dascyllus aruanus. Ecology 53: 741-744

Sale, P. F. (1972b). Effect of cover on agonistic behavior of a reef fish: a possible spacing mechanism. Ecology 53: $753-758$

Sale, P. F. (1977). Maintenance of high diversity in coral reef communities. Am. Nat. 111: 337-359

Sale, P. F. (1978). Coexistence of coral reef fishes - a lottery for living space. Env. Biol. Fish. 3: 85-102

Sale, P. F. (1979). Recruitment, loss and coexistence in a guild of territorial coral reef fishes. Oecologia 42: 159-178

Sale, P. F. (1980a). The ecology of fishes on coral reefs. Oceanogr. mar. Biol. A. Rev. 18: 367-421

Sale, P. F. (1980b). Assemblages of fish on patch reefs predictable or unpredictable? Env. Biol. Fish. 5: 243-249

Sale, P. F., Douglas, W. A. (in press). Precision and accuracy of visual census technique for fish assemblages on coral patch reefs. Env. Biol. Fish.

Sale, P. F., Dybdahl, R. (1975). Determinants of community structure for coral reef fishes in an experimental habitat. Ecology 56: 1343-1355

Sale, P. F., Dybdahl, R. (1978). Determinants of community structure for coral reef fishes in isolated coral heads at lagoonal and reef slope sites. Oecologia 34: 57-74

Smith, C. L. (1978). Coral reef fish communities: a compromise view. Env. Biol. Fish 3: 109-128

Suarez, S. S. (1975). The reproductive biology of Ogilbia cayorum, a viviparous brotulid fish. Bull. mar. Sci. 25 143-175

Talbot, F. H., Russell, B. C., Anderson, G. R, V (1978). Coral reef fish communities: unstable, high-diversity systems? Ecol. Monogr. 48: 425-440

Thresher, R. E. (in press a). Reproduction in reef fishes, Tropical Fish Hobbyist, Neptune City, New Jersey

Thresher, R. E. (in press b). Habitat effects on the reproductive success of the coral reef fish Acanthochromis polyacanthus (Pomacentridae). Ecology

Williams, D. M. (1979). Factors influencing the distribution and abundance of pomacentrids (Pisces: Pomacentridae) on small patch reefs in the One Tree lagoon (Great Barrier Reef). University of Sydney, Ph.D. Dissertation

Williams, D. M. (1980). Dynamics of the pomacentrid community on small patch reefs in One Tree lagoon (Great Barrier Reef). Bull. mar. Sci. 30: 159-170

Zar, J. H. (1974). Biostatistical analysis, Prentice-Hall Englewood Cliffs, New Jersey 